\title{
REPRESENTAÇÕES SOCIAIS DO AUTISMO PARA PROFISSIONAIS DO APOIO LOGÍSTICO DA ASSOCIAÇÃO DE PAIS E AMIGOS DOS AUTISTAS DA REGIÃO CARBONÍFERA DE SANTA CATARINA
}

\author{
SOCIAL REPRESENTATIONSOF AUTISM FOR PROFESSIONALS OF LOGISTIC \\ SUPPORTOFTHE ASSOCIATION OF COUNTRY AND FRIENDS OF AUTISTS IN
}

\author{
THE CARIBBEANREGION OF SANTA CATARINA
}

Tamires Rosa Pacheco ${ }^{1}$, Maicol de Oliveira Brognoli², Gian de Oliveira Réus ${ }^{3}$, Caroline Pereira Fernandes ${ }^{4}$, Amanda Castro ${ }^{5}$

\begin{abstract}
RESUMO
Este estudo buscou compreender as representações sociais de profissionais que atuam no apoio logístico da Associação de Pais e Amigos dos Autistas da região Carbonífera de Santa Catarina, sobre o Transtorno de Espectro Autista (TEA). Para a coleta de dados utilizou-se um roteiro de entrevista com oito itens referentes à temática das representações sociais, como também, sobre seus sentimentos e conhecimentos em relação ao TEA. Estas informações foram transcritas e analisadas por meio de análise de conteúdo. Concluiu-se que as representações sociais sobre a origem do TEA circularam dentre diversas vertentes teóricas, algumas falas o conhecimento científico foram transpostas pelo conhecimento do senso comum, encontrou-se também representações relacionadas à religiosidade em que nascer autista seria uma espécie de lição divina. Concluiu-se também que os funcionários entrevistados precisam de capacitação e sensibilização contínua, a fim de promover o acesso às informações sobre o TEA, favorecendo a qualidade das relações e intervenções nestas instituições.

Palavras-chave: Representações sociais; Espectro autista; Funcionários.
\end{abstract}

\footnotetext{
ABSTRACT

This study sought to understand the social representations of professionals who work in the logistic support of the Autism Association of Parents and Friends of the Carboniferous region of Santa Catarina, on Autism Spectrum Disorder. In front of the professional of the logistic support, and to verify how is the knowledge of the same about the disorder already mentioned for the data collection, an interview script was used with eight items referring to the theme of social representations, as well as their feelings and knowledge. This is information, was transcribed and analyzed. It was concluded that the social representations about the origin of the AED circulated among several theoretical, Some speeches the scientific knowledge were

${ }^{1}$ Acadêmica da $8^{\text {a }}$ fase do curso de Psicologia da Universidade do Extremo Sul Catarinense- UNESC.

${ }^{2}$ Acadêmica da $6^{\mathrm{a}}$ fase do curso de Psicologia da Universidade do Extremo Sul Catarinense- UNESC.

${ }^{3}$ Acadêmica da $6^{\mathbf{a}}$ fase do curso de Psicologia da Universidade do Extremo Sul Catarinense- UNESC.

${ }^{4}$ Acadêmica da $6^{\mathrm{a}}$ fase do curso de Psicologia da Universidade do Extremo Sul Catarinense- UNESC.

${ }^{5}$ Doutoranda em Psicologia na Universidade Federal de Santa Catarina. Professora na Universidade do Extremo Sul Catarinense. E-mail: amandacastrops@gmail.com.
} 
transposed by the knowledge of the common sense, was also found representations related to the religiosity in which to be born autism would be a species of divine lesson. It is, was also concluded that the employees interviewed need continuous training and awareness in order to promote a better knowledge of them, to improve the quality of relations and interventions in these institutions.

Keywords: Social representations; Autistic spectrum; Employees.

\section{INTRODUÇÃo}

$\mathrm{Na}$ atualidade, o Transtorno do Espectro Autista (TEA) está inserido no grupo de perturbações globais do desenvolvimento, sendo denominado como uma perturbação neurobiológica complexa. Em cada 1000 crianças 3 a 6 talvez venham a ser diagnosticadas como autistas, podendo ser de diversos grupos raciais, étnicos ou sociais e podendo atingir 4 a 5 vezes mais o sexo masculino em relação ao sexo feminino (ALEXANDRE, 2010; FREITAS, 2015).

O TEA manifesta-se nas crianças antes dos três anos de idade, e é uma deficiência grave e crónica que compromete seu desenvolvimento biológico, familiar e social, trazendo incapacidades durante toda a vida para o indivíduo que a possui. A autores que relacionam o referido transtorno com disfunções biológicas do sistema nervoso central (FREITAS, 2015).

Este transtorno é atípico e se manifesta de forma heterogênea, com grande variabilidade na apresentação clínica e com diferentes níveis de gravidade. Podemos encontrar crianças que falam e outras que não, ou às vezes crianças sem qualquer tipo de contato social e outras com relações atípicas. Algumas crianças podem apresentar atraso intelectual, enquanto outros podem ter um quociente inteligente dentro da média normal (MARTELETO et al, 2008). Estes sintomas podem ser verificados pela anamnese, observação comportamental, exames ou entrevistas com o indivíduo e familiares (AMA, 2016).

Os critérios para diagnostico do transtorno do espectro autista têm evoluído com o passar dos anos. Até 1980, autismo não era considerado como uma entidade separada da esquizofrenia. Em 1987, o DSM-III-R instituiu critérios diagnósticos com uma perspectiva de desenvolvimento, e foram estabelecidos dois diagnósticos, encampados sob o termo transtorno invasivo (ou global) do desenvolvimento: (1) autismo; e (2) transtorno invasivo (ou global) do desenvolvimento não-especificado (TID-NE). Hoje é chamado de TEA conforme o Manual Diagnóstico e Estatístico de Transtornos Mentais (DSM-V) (GADIA et al., 2004). 
É importante para os indivíduos com espectro autista a constante estimulação por parte daqueles que os rodeiam, assim como a consistência das estratégias e rotinas utilizadas. É necessário que entendam as características do mesmo, qual a melhor forma de interagir com eles e de responder às suas necessidades e interesses (FREITAS, 2015).

$\mathrm{O}$ afeto é um ingrediente primordial em qualquer relação humana, e que este deve estar presente em todas as fases da vida do indivíduo (SILVA, 2013). Compreende-se então, que o profissional que atua na educação, aprendizagem, cuidado e no desenvolvimento dos mesmo, são figuras importantes neste processo, e através de entrevistas com os mesmos podemos relatar ricas informações sobre os comportamentos dos portadores do TEA (SILVA, 2013)

Partindo desta realidade, percebeu-se a necessidade de se realizar uma pesquisa em uma das instituições que prestam este serviço, a Associação de Pais e Amigos dos Autistas da Região Carbonífera de Santa Catarina (AMA). Contudo, compreende-se que em uma instituição especializada, são muitos os profissionais que dedicam-se na mediação dos indivíduos portadores do TEA. Pode-se citar especialistas como: pedagogos, psicólogos, neurologistas, fonoaudiólogos, entre outros. E também é possível destacar outra categoria, não menos importante, que presta trabalho voltado ao apoio logístico à instituição e que convive de modo indireto com os indivíduos que apresentam o referido Transtorno; que são os que trabalham no setor da alimentação, transporte, manutenção, segurança, higienização e etc.

Sob este prisma, pretendeu-se realizar a pesquisa com estes últimos profissionais citados, e identificar suas representações sociais sobre o autismo, e analisar também, seus sentimentos nas suas variadas formas de interação com o portador do TEA.

Santos (2005, p. 22) explana que:

Em Psicologia Social, representações sociais são descritas como teorias do senso comum, elaboradas em torno de objetos culturalmente significativos para determinado grupo. Essas teorias leigas têm a função de dar sentido à realidade social, produzir identidades, organizar informações e orientar condutas.

Vala (2006, p. 502) explica, “a dimensão funcional e prática das representações sociais são manifestadas na organização dos comportamentos, nas atividades comunicativas, na argumentação e na explicação quotidianas, e na diferenciação dos grupos sociais”. Portanto, as representações sociais proporcionam o acesso às justificações utilizadas para orientar a interpretação humana sobre a sua realidade. Elas possibilitam a compreensão das estratégias 
utilizadas pelos indivíduos para compreenderem fatos ou situações com as quais não estão familiarizados. Devido a isso, reconstroem as situações como conhecimentos que vão influenciar no processo de comunicação e interação com diferentes situações e fenômenos (MOSCOVICI, 1961; CASTELA, 2013).

Temos a hipótese que estes sujeitos que prestam apoio logístico a instituição passam pelo fenômeno da invisibilidade social. Não são cientificamente considerados os mais adequados e especializados a falar sobre o tema transtorno de espectro autista, porém convivem cotidianamente com esta situação, preparados ou não, representando sua realidade profissional e social de algum modo. Segundo Weisheimer (2013), a invisibilidade social, se refere a situações em que determinados sujeitos se encontram imperceptíveis nas relações sociais. É uma ação social que implica em não ver o outro, fechar os olhos para a sua existência social e tudo que decorre deste fato.

As concepções dos profissionais do apoio logístico, permitem entender a natureza e qualidade de suas relações e intervenções. Desejou-se com esta pesquisa questionar e apresentar ao leitor como está o nível de conhecimento deles frente ao objetivo principal da associação, que é a pessoa com TEA, e sem preocupação com a fidedignidade científica desse saber.

\section{MATERIAIS E MÉTODO}

Esta pesquisa de campo é caracterizada como exploratória-descritiva e de caráter qualitativo, cujo intuito visa compreender, de forma adequada, o fenômeno estudado, para fins de produção de conhecimento científico. Foi realizada uma entrevista semi-estruturada com os profissionais do apoio logístico da Associação de Pais e Amigos do Autista (AMA). A pesquisa foi realizada na própria associação, em apenas um encontro, no período vespertino, durante o período de trabalho dos mesmos. Anteriormente, realizou-se um pedido via telefone para a associação requerendo um visita, ocasião em que os pesquisadores solicitaram a realização da pesquisa. A partir do interesse dos participantes, foi distinguido uma data para esclarecer os propósitos desta pesquisa, e pelo aval positivo da gestora aplicar o questionário com os mesmos. A instituição aceitou a carta de apresentação e rubricou a mesma. Os participantes assinaram o Termo de Consentimento livre e Esclarecido para a autorização de sua participação na pesquisa. 
Para a coleta de dados utilizou-se um roteiro de entrevista que continha oito itens referentes à temática das representações sociais, como também, suscitava que falassem sobre seus sentimentos e conhecimentos com relação ao indivíduo com Transtorno do Espectro Autista (TEA). Foi utilizado um gravador para fins de registrar as respostas da entrevista semi-estruturada, visando uma melhor apreensão de todos os dados a partir da revisão da gravação.

Os participantes desta pesquisa foram profissionais que atuavam direta ou indiretamente com os indivíduos portadores de TEA da AMA do Bairro São Cristóvão da cidade de Criciúma, Santa Catarina. Os profissionais entrevistados que devidamente aceitaram participar da pesquisa, eram da área da higienização, transporte, alimentação e manutenção. Todos possuíam escolaridade média, dois eram do sexo feminino e dois do sexo masculino.

Após as entrevistas com os profissionais, as informações foram transcritas pelos pesquisadores que, posteriormente, realizaram uma análise de conteúdo com base nos dados obtidos.

\section{RESULTADOS E DISCUSSÃO}

Os participantes foram entrevistados inicialmente acerca de suas motivações e sentimentos em relação ao trabalho exercido na instituição. O primeiro participante referiu. “Eu me sinto muito bem, vários casos de crianças que entrou aqui com quatro anos de idade, tudo que comia era batido no liquidificador, e uma professora a ajudava na parte da mastigação, e tem professoras que ficam duas horas esperando eles a fazerem xixi, coisa que os pais não fazem, em muitos caso né, que o dia que a que não comia começou a comer com colher foi uma coisa que emocionou, me sinto muito bem, pena eu não saber muito mais do autismo” (SIC) (Participante 1, trabalha no transporte e na manutenção, está há onze anos na Associação de Pais e Amigos do Autista (AMA).

Em seu discurso o participante evidencia a valorização do trabalho dos profissionais de educação, sua paciência e dedicação, ele fala também que os pais não teriam essa paciência, e não são todos os centros que possuem este nível de atendimento com atenção. Estudos realizados na área do autismo provam que os comportamentos destas crianças variam de contexto para contexto, determinadas competências adquiridas em uma situação não se generalizam, é necessário que o educador em todos os contextos mantenha o mesmo modo 
para que o indivíduo com Transtorno do Espectro Autista (TEA) possa adquirir competências. Por isto, é necessário reforçar a ideia de que tem de haver um trabalho conjunto e contínuo entre a escola e a família (CRUZ et al., 2010).

Em relação às causas do autismo é citada a responsabilidade materna: "Talvez um pouco de cuidado da mãe na gestação, cuidado em ir no médico e fazer pré natal, ou não ter condições de realmente poder se cuidar na gravidez, ou talvez é um problema de fumar de mais, e isso vai no sangue da criança, ou pode ser de geração, tem algumas que vem com algum problemas e algumas que não" (SIC) (Participante 2, trabalha na higienização, está há um ano na AMA).

Essa profissional, fala ainda que o autismo pode ter sua origem em decorrência da ausência dos cuidados pré-natais da mãe, ao uso de drogas, à falta de realização de exames completos. É possível identificar que as representações sociais dessa participante trazem a gênese do autismo associada à culpa direcionada a mãe. De modo similar em pesquisa de Meimes et al., (2015) revela que o impacto do diagnóstico para a mãe parece ter sido demarcado por muita culpa, considerando-se culpada a mãe tende a atribuir para a si a responsabilidade pelos cuidados com o manejo da situação familiar.

Sobre as expectativas na atuação com os indivíduos com TEA, uma participante afirma: "Eu antes estava desempregado. Antes eu achava que elas eram violentas, mas são diferentes do que eu imaginava, são bem tranquilas" (SIC) (Participante 4, trabalha na manutenção, está há cinco meses na AMA).

Por meio de seu relato, compreende-se que a crença de que as pessoas autistas são violentas fizeram parte das expectativas iniciais do entrevistado, sendo superadas com a experiência do trabalho. Estas expectativas podem ser explicadas devido ao seguinte fato:

\footnotetext{
Existem formas mais graves onde crianças com autismo podem apresentar comportamento destrutivo, auto-agressivo e forte resistência à mudanças. Há ainda crianças com níveis de inteligência mais preservados, onde é possível observar determinadas habilidades bastante desenvolvidas, as quais podem constituir verdadeiros talentos relacionados a sensibilidade musical, habilidades matemáticas, memorização, desenhos e pinturas, dentre outros (AMA, 2016).
}

Sobre a concepção do autismo destaca-se a fala do seguinte entrevistado: "Não sei responder o que é o autismo, acho um problema explicar, interajo como eles como se fosse normais" (SIC) (Participante 1, trabalha no transporte e na manutenção, está há onze anos na AMA). 
A cristalização de atributos que as classificações diagnósticas geralmente apontam é temerária, especialmente na infância, tendo em vista que o padrão de normalidade é questionável e dificulta o atendimento do indivíduo em sua integralidade, tendo em vista a busca incessante por um padrão considerável “normal” (LÓPEZ; SARTI, 2013).

As representações sociais do autismo parecem associadas à deficiência, conforme segue: "Não! Tenho um caso na família minha mãe, só que é deficiência mental, não consegue associar uma coisa à outra, a doença física no caso em cada perna" (SIC) (Participante 1, trabalha como motorista e na manutenção, está há onze anos na AMA). Aqui acontece o fenômeno chamado na psicologia social de ancoragem social. "Ancoragem é o outro processo, aquele que dá sentido ao objeto que se apresenta à nossa compreensão. Tratase da maneira pela qual o conhecimento se enraíza no social e volta a ele" (ARRUDA, 2002). Ele usa esta ancoragem como associação à deficiência quando perguntamos se tem algum caso na família, ele lembra de um caso de deficiência em sua família.

Em sua fala acerca do indivíduo com espectro autista um dos participantes traz um discurso a respeito da normalidade: "O autista tem o mundo dele e o nosso, ao mesmo tempo que ele está conversando contigo ele já não está mais, ele entra em outro mundo, o autista só faz o que ele quer, o que ele não quer ele não faz, até faz mas olha, é pior que criança normal, ele bate o pé e não faz mesmo, se fizermos todas as vontades dele ele vai ser uma criança normal a partir que você contrariar ele se altera do nada, ele foge da realidade dele, ele se altera" (SIC) (Participante 1, trabalha no transporte e na manutenção, está há onze anos na AMA).

A concepção que se tem de uma pessoa com espectro autista é de alguém que foge dos padrões normativos. Carvalho (2009) explana que "deve-se levar em consideração que por serem consideradas como crianças que fogem de um padrão normalizado estas muitas vezes são prejudicadas em relação ao acesso e o convívio".

Quando o participante citado anteriormente fala que se fazer as vontades dele ele vai ser como uma "criança normal", remete a condição do autista de ter sua percepção centrada em si mesmo, só fazendo o que realmente lhe interessa (suas vontades). "A palavra autismo vem do Grego autos, que significa "próprio", denominando uma condição onde o indivíduo anularia a percepção do que está ao seu redor e centrando-se em si mesmo" (MONTAGNER et al., 2007). 
Também em várias partes de sua narrativa ocorre contradições, mostrando o quanto esse assunto o confunde, exemplo: na parte "que se fazer as vontades vai ser como uma criança normal", e depois fala "se bem que todos são normais", apresentando ai desse modo uma contradição, expressando sua confusão e sua falta de informação. Verifica-se aqui uma possível zona muda da representação social do autismo, encoberta por um discurso que revela a questão da desejabilidade social. A zona muda faz parte da consciência dos indivíduos, porém não é verbalizada quando o indivíduo ou grupo não pretendem fazer menção a determinado conteúdo público ou explicitamente (ABRIC, 2005).

$\mathrm{O}$ indivíduo entrevistado demonstra na narrativa que a origem do autismo deve ser genética/hereditária, conforme o trecho: "Ele vem da genética, muitos pais já tem uma coisa puxando de distúrbio por um lado emocional, e com o passar do tempo vai se manifestando para pior" (SIC) (Participante 1, trabalha no transporte e na manutenção, está há onze anos na AMA).

Realmente o autismo tem uma grande etiologia genética, porém ainda não se sabe o real fator causador desse transtorno, ou onde está localizado, em que parte do cérebro.

As Perturbações do Espectro do Autismo (PEA) são um grupo de doenças com uma forte etiologia genética que afetam o neurodesenvolvimento, caracterizando-se por dificuldades na interação social e comunicação e comportamentos repetitivos e estereotipados (COELHO, 2012).

No que se refere ao indivíduo autista um dos entrevistados afirma: "Uma pessoa que precisa de outra, dos professores, dos pais, pessoas que necessitam de nós aqui na terra, que estamos ali do lado deles para ajudar. São pessoas que não sabem o que é certo, e temos que estar ali do lado deles para ajudar" (SIC) (Participante 2, higienização, está há um ano na AMA).

Ela se refere a uma constante dependência, sempre alguém vai cuidar. Normalmente seria a família, mas nem sempre é ela que cuida, ou ele não tem família para cuidar. Se ele ficar dependente muito tempo vai acabar sobrecarregando seus cuidadores, podendo causar adoecimentos aos mesmos.

As dificuldades pertinentes ao transtorno devido à sua cronicidade, condições físicas e mentais resultam em uma maior dependência em relação às suas mães, sendo elas a principal cuidadora dos portadores de autismo e, por isso, está mais propensa ao desenvolvimento de altos níveis de estresse, resultando em sobrecarga, agravos à saúde física e psicológica (TABAQUIM et al., 2015). 
Sobre a comunicação com os autistas um dos entrevistados afirma: "É difícil pra ela com aquele problema, não poder falar, não poder escutar, tem umas que não falam. As vezes ela quer falar e não pode, daí ela chora. Só se tiver alguém dando apoio, mas sozinho é difícil. A não ser que com o tempo ela comece a falar" (SIC) (Participante 2, trabalha na higienização, está há um ano na AMA).

Para Luria (1979), [...] a linguagem imprime ao menos três mudanças essenciais à atividade consciente do homem. A primeira dessas mudanças consiste em que designam os objetos e eventos do mundo exterior com palavras isoladas ou combinadas, a linguagem permite discriminar esses objetos, dirigir atenção para eles e conservá-los na memória. Resulta daí que o homem está em condições de lidar com os objetos do mundo exterior inclusive quando eles estão ausentes. [...] (p.80)

A participante citada a cima põe a linguagem como forma de aquisição da autonomia dessa pessoa com TEA. Vemos que a linguagem tem realmente grande importância da vida de uma pessoa, bem como na aquisição da autonomia, mas não utilizar a linguagem falada não exclui a possibilidade de aquisição de autonomia. Apesar da valorização da verbalização para a comunicação é necessário refletir acerca das diversas formas de comunicação possível. Pois, através da comunicação não verbal transmitimos mensagens por signos, por meio da expressão facial, da linguagem corporal, das características físicas. Conhecer as diversas formas de comunicação de cada indivíduo torna-se crucial para manutenção de uma interação de qualidade (SANTOS; SHIRATORI, 2005).

Sobre a forma de viver do autista, um dos entrevistados responde: "Pra mim acho que cada autista tem o seu jeito de viver, suas manias. Eles não são diferentes, mas as manias deles são diferentes da nossa. Quando vejo o autista lembro de teimosia" (SIC) (Participante 4, trabalha na manutenção, está há cinco meses na AMA).

Neste sentido conforme Coelho (2012) parece haver uma heterogeneidade no desenvolvimento das funções cognitivas e sociais de cada indivíduo com espectro autista, desse modo, a estereotipia apenas atrapalha a necessidade de considerar individualmente cada caso para facilitar o processo de interação social.

A ancoragem da representação social do autismo parece ainda ancorada na ideia de doença, conforme exemplificado no trecho da entrevista: "O autismo pra mim é uma criança doente, uma pessoa doente, uma pessoa com deficiências. Tenho um vizinho autista, ele até está aqui na escola, eu convivo normal com ele. Ele é bem querido, ele brinca, é normal, 
claro tem os limites dele" (SIC) (Participante 3, trabalha na alimentação, está há quatro meses na AMA). Conforme Santos e Santos (2012) existe algo essencialmente difícil de ser compreendido sobre o autismo, incertezas inclusive no campo científico, que escapam de uma ancoragem definitiva e gera um sentimento massivo de incerteza individual e coletivo, o que pode corroborar com a tentativa de simplificação associando o autismo à doença.

Em outra perspectiva uma participante aponta aspectos de religiosidade em sua representação social do autismo: "Deus deixou ele assim pra dar a ele um exemplo, uma lição para as outras pessoas que tem tudo e ao mesmo tempo acham que não tem nada. E vendo aquela pessoa ali é melhor pra olhar mais pra dentro, por que eles são diferentes, mas tem uns que são diferentes e parecem ser melhores do que nós que somos normais" (SIC) (Participante 3, trabalha na alimentação, está há quatro meses na AMA). Assim, a entrevistada vê a condição autista como uma lição divina, para as outras pessoas ditas normais que estão no entorno do autista. Esta representação está imantada por uma compreensão religiosa fundada nas concepções de pecado x castigo x aprendizado pelo sacrifício. Gomes (2004, p. 52) nos esclarece quanto ao papel da religiosidade nas representações sociais:

A religião é apontada por Berger como o instrumento mais amplo de legitimação da realidade, inclusive da social. Essa legitimação é que mantém a realidade socialmente definida. A religião legitima de modo eficaz, porque funde as tênues realidades do mundo social com as pretensas realidades do mundo sagrado, colocando a realidade para além das contingências dos sentidos humanos e das atividades sociais, criando numa pretensa supra-realidade a sua própria realidade.

Ainda nesse sentido completa a participante: "Ele veio assim, pra unir as famílias. Uns une, outros separam. Às vezes pra amadurecer aquela pessoa (família), talvez aquela pessoa que despreza as outras. Daí veio assim na família pra ver que é diferente, pra mostrar, pra ver se essa pessoa muda, se as pessoas pensam na vida" (SIC) (Participante 3, trabalha na alimentação, está há quatro meses na AMA). Neste relato, a participante demonstra uma percepção do autista a partir de uma missão sacrificial para amadurecer as pessoas, ocasionar mudanças.

A relação entre autismo e ausência de autonomia é destacado no seguinte trecho: " $A$ vida futura dele se não tiver uma pessoa pra ajudar, vai ficar jogada. Por que se já uma pessoa normal sendo desprezada já tem muitos que ficam jogado no mundo. Uma pessoa assim então, ou morreria ou sei lá, ia viver junto com os animais” (SIC) (Participante 3, trabalha na alimentação, está há quatro meses na AMA). Desse modo, a entrevistada compreende o autista como um ser sem autonomia, que sem os devidos cuidados morreria, ou 
viveria junto com os animais. Santos e Santos (2012, p. 369) por meio de um estudo feito com professoras acerca das suas representações sociais sobre o autismo infantil, destaca a partir de seus resultados a ideia de um mundo "pobre" ligado a um mundo vazio, sem atividade inteligente, ou então um mundo com uma inteligência extraordinária. Estes mesmos professoras entrevistados alegam que o autista está em uma condição próxima a de um animal, relacionado ao "afeto puro" e pouca ou nenhuma racionalidade.

Sobre a maneira de interagir com o indivíduo com TEA um dos participantes aponta: “vou responder o que eu sempre faço. Eu perguntaria para o professor, para a psicóloga dele ou para Fono, os defeitos, o que ele gosta, o que ele não gosta, ele fala, ele ouve, e a partir dali eu tentaria achar um jeito de chegar naquela criança, para conversar com ela. $O$ profissional pensaria que ele estaria no mundo dele, sabe-se lá com quem" (SIC) (Participante 1, trabalha no transporte e na manutenção, está há onze anos na AMA)

Ele demonstra nessa narrativa uma inteligência muito grande, e os conceitos que temos hoje em dia de inclusão social, de não fazer com que a pessoa com deficiência se adeque a nossa realidade, mas sim entrar no contexto desta pessoa e preparar o ambiente para ela, ou seja se adequar ao modo dela de ser.

Fala do entrevistado: "Eu brinco com eles o tempo todo, cada um brinca de um tipo, uns a gente abraça, outros a gente brinca de correr atrás, brinca que vai morder, cada um tem um jeito" (SIC) (Participante 1, trabalha no transporte e na manutenção da escola, está há onze anos na AMA). O brincar foi a forma como esse profissional, adotou para se comunicar com as crianças. A utilização do lúdico para comunicação com os indivíduos com TEA, é bem funcional mediante sua dificuldade de comunicação simbólica. Conforme Sanini et al., (2013) a habilidade para engajar-se em jogos/brincadeiras complexas está associada a uma maior presença de comportamentos pró-sociais e a uma menor agressividade na idade escolar.

Em relação à interação com os indivíduos com TEA destaca-se a participante: “Eu interajo de manhã com eles a hora que eles chegam, eu espero eles chegarem, coloco o café, e às vezes quando as professoras estão aqui embaixo com eles, as vezes eles conversam com a gente, tem vezes que a gente entende" (SIC) (Participante 3, trabalha na alimentação, está há quatro meses na AMA). Neste sentido sua interação com os indivíduos com TEA é de cunho profissional e não interpessoal. Interage em momentos específicos necessários a sua função profissional, esperando a iniciativa de conversação partir dos indivíduos com TEA. No entanto, conforme Gusmão et al., (2015) por meio da convivência na escola o aluno poderá 
descobrir o afeto, carinho, convívio com outras crianças, a importância de compartilhar sentimentos e interesses, já as rotinas diárias o ajudarão em sua independência e autonomia.

\section{CONCLUSÃo}

Conclui-se que conhecer as características das representações sociais destes profissionais do apoio logístico é necessário para auxiliá-los neste processo interacional tão complexo. As representações sociais apresentadas pelos profissionais sobre a origem do autismo circularam dentre diversas vertentes teóricas, uns defenderam a ideia genética, já outros estão voltadas as relações objetais no período gestacional. Em algumas falas o conhecimento científico foi transposto pelo conhecimento do senso comum. Também encontrou-se uma mais teológica representando que nascer autista seria lição divina para dar exemplos as outras pessoas. Porém o profissional entrevistado pode não ser cientificamente considerados os mais adequados e especializados a falar sobre como o Transtorno do Espectro Autista, porém convivem cotidianamente com esta situação, preparados ou não, representam sua realidade profissional e social de algum modo.

Esta mesma pesquisa pode oferecer dados para novas questões a serem investigadas, como a hipótese de os mesmos profissionais terem invisibilidade na sociedade. Por fim a partir da análise dos dados, concluímos que os funcionários do apoio logístico desta associações precisam ser mais bem escutados e estimulados para que possam cada vez mais, ter voz ativa, precisam também estarem envolvidos em um clima de sensibilização e continuada capacitação para a compreensão do Transtorno do Espectro Autista (TEA). Capacitar os profissionais com possíveis invisibilidades sociais lhes trará um devido empoderamento, melhorando o trabalho prestado, e as relações e os resultados certamente serão cada vez mais positivas, somando assim mais ganhos no dia a dia do autista institucionalizado e verificando melhores maneiras de interação entre ambos.

\section{REFERÊNCIAS}

ABRIC, J. C. A zona muda das representações sociais. In D. C. OLIVEIRA \& P. H. F. CAMPOS (Orgs), Representações Sociais - Uma teoria sem fronteiras. Rio de Janeiro: Museu da República, 2005. p. 23-34.

AMA REC/Santa Catarina. E.E. Mundo. Virtual Mídia. Disponível <http://www.amigosdoautista.com.br/oautismo.htm> Acesso em: 12 de nov. 2016. 
ARRUDA, A. Teoria das representações sociais e teorias de gênero. Cadernos de pesquisa. Universidade do Rio de janeiro. n. p. 127-147, nov.2002. Disponível <http://www.scielo.br/pdf/cp/n117/15555.pdf>. Acesso em 12 de nov. 2016.

CASTELA, C. A. Representações sociais e atitudes face ao autismo. Dissertação Mestrado em Psicologia da Educação. Universidade do Algarve. Portugal, 2013.

CARVALHO, R. Inclusão e escolarização de alunos autistas. Pedagogia em Ação. v. 1, n. 1, p. 111-114, 2009. Disponível <http://periodicos.pucminas.br/index.php/pedagogiacao/article/view/658/673>. Acesso em: 12 de nov. 2016.

COELHO, J. I. N. Genética molecular das Perturbações do Espectro do Autismo: Análise de variantes estruturais. 2012.102 f. Dissertação (Mestrado Biologia- Biologia Humana e Ambiente). Universidade de Lisboa, Faculdade de Ciências.

CRUZ, C. et al. Criança autista: pais e professores-uma parceria de sucesso no desenvolvimento de competências. Millenium-Journal of Education, Technologies, and Health, n. 39, p. 89-107, 2016. Disponível: 〈http://hdl.handle.net/10400.19/472〉. Acesso em: 12 nov. 2016.

FREITAS. C. S. G. Necessidades Formativas dos Educadores de Infância e dos Auxiliares de Ação Educativa na Prática Profissional com Crianças Autistas no Funchal. Portugal, p. 127, 2015. Dissertação (Mestrado em Ciências da Educação: Educação Especial), Universidade Fernando Pessoa. Disponível <http://bdigital.ufp.pt/bitstream/10284/4912/1/DMCarla\%20Freitas.pdf >. Acesso em: 13 de nov. 2016.

GADIA, C. A et al. Autismo e doenças invasivas de desenvolvimento. Jornal de Pediatria. v. $80, \quad$ n. 2004.202 Disponível <http://www.scielo.br/pdf/jped/v80n2s0/v80n2Sa10.pdf>. Acesso em: 12 nov. 2016.

GOMES, A. M. A. As representações sociais e o estudo do fenômeno do campo religioso. Rev. Ciências da Religião: História e Sociedade, São Paulo, v. 2, n. 2, 2004. Disponível

<http://www3.mackenzie.br/editora/index.php/cr/article/view/2315/2164>. Acesso em: 20 nov. 2016.

LÓPEZ, R. M. M.; SARTI, C. Eles vão ficando mais próximos do normal. Considerações sobre normalização na assistência ao autismo infantil. Idéias.Revista do Instituto de Filosofia e Ciências Humanas - UNICAMP, v. 4, n. 1, 2013. Disponível < http://www.ifch.unicamp.br/ojs/index.php/ideias/article/view/1394/968>. Acesso em 12 nov. 2016.

MEIMES, M. A.; SALDANHA, H. C.; BOSA, C. A. Adaptação materna ao transtorno do espectro autismo: relações entre crenças, sentimentos $\mathrm{e}$ fatores psicossociais.PsicoPorto Alegre, v. 46, n. 4, p. 412-422, dez. 2015. Disponível < http://pepsic.bvsalud.org/pdf/psico/v46n4/02.pdf>. Acesso em 12 nov. 2016.

SANINI, C.; et al. Competência social e autismo: o papel do contexto da brincadeira com Pares. Psicologia: Teoria e Pesquisa, v. 29, n. 1, p. 99-105, 2013. Disponível < http://www.scielo.br/pdf/ptp/v29n1/12.pdf>. Acesso em: 12 nov. 2016. 
SANTOS, M. F. S. (2005). A Teoria das Representações Sociais. In M. F. S. Santos \& L. M. Almeida (Orgs.), Diálogos com aTeoria das Representações Sociais (pp. 15-38). Recife: Ed. Universitária da UFPE/ UFAL.

SANTOS, C.C. V.; SHIRATORI, K. A influência da comunicação não verbal no cuidado de enfermagem. RevBrasEnferm. p. 434-7, 2005. Disponível <http://www.scielo.br/pdf/reben/v58n4/a10v58n4.pdf>. Acesso em: 12 nov. 2016.

SANTOS, M. A.; SANTOS, M. F. Representações sociais de professores sobre o autismo infantil. Psicologia \& Sociedade, v. 24, n. 2, p. 364-372, 2012. Disponível <

http://www.scielo.br/pdf/psoc/v24n2/13.pdf>. Acesso em: 12 nov. 2016.

TABAQUIM, M. L.M. et al. Autoeficácia de cuidadores de crianças com o transtorno do espectro autista. Revista Psicopedagogia. v.32, n. 99 p. 285-292, 2015. Disponível: <http://pepsic.bvsalud.org/pdf/psicoped/v32n99/02.pdf.>. Acesso em: 20 nov. 2016.

VALA, J. Representações sociais e psicologia social do conhecimento quotidiano. In: J. VALA; M. B. MONTEIRO, Psicologia Social. Lisboa: Fundação CalousteGulbenkian, 2006. p. 57-502.

WEISHEIMER, N. Sobre a invisibilidade social das juventudes rurais. Desidades, v. 1, p. 2227, 2013. 